\title{
PRELIMINARY REPORT ON LOSS-OF-FLOW CALCULATIONS \\ FOR THE CRBR DEMONSTRATION PLANT
}

\section{by}

H. H. Hummel and P. Pizzica

Reactor Safety Appraisals Technica1 Memorandum Number 1

Work performed under the auspices of the U.S. Atomic Energy Commission 


\section{DISCLAIMER}

This report was prepared as an account of work sponsored by an agency of the United States Government. Neither the United States Government nor any agency Thereof, nor any of their employees, makes any warranty, express or implied, or assumes any legal liability or responsibility for the accuracy, completeness, or usefulness of any information, apparatus, product, or process disclosed, or represents that its use would not infringe privately owned rights. Reference herein to any specific commercial product, process, or service by trade name, trademark, manufacturer, or otherwise does not necessarily constitute or imply its endorsement, recommendation, or favoring by the United States Government or any agency thereof. The views and opinions of authors expressed herein do not necessarily state or reflect those of the United States Government or any agency thereof. 


\section{DISCLAIMER}

Portions of this document may be illegible in electronic image products. Images are produced from the best available original document. 
The facilities of Argonne National Laboratory are owned by the United States Government. Under the terms of a contract (W-31-109-Eng-38) between the U. S. Atomic Energy Commission, Argonne Universities Association and The University of Chicago, the University employs the staff and operates the Laboratory in accordance with policies and programs formulated, approved and reviewed by the Association.

\section{MEMBERS OF ARGONNE UNIVERSITIES ASSOCIATION}

The University of Arizona

Carnegie-Mellon University

Case Western Reserve University

The University of Chicago

University of Cincinnati

Illinois Institute of Technology

University of Illinois

Indiana University

Iowa State University

The University of Iowa
Kansas State University The University of Kansas Loyola University Marquette University Michigan State University The University of Michigan University of Minnesota University of Missouri Northwestern University University of Notre Dame
The Ohio State University

Ohio University

The Pennsylvania State University

Purdue University

Saint Louis University

Southern Illinois University

The University of Texas at Austin

Washington University

Wayne State University

The University of Wisconsin

\section{NOTICE}

This report was prepared as an account of work sponsored by the United States Government. Neither the United States nor the United States Atomic Energy Commission, nor any of their employees, nor any of their contractors, subcontractors, or their employees, makes any warranty, express or implied, or assumes any legal liability or responsibility for the accuracy, completeness or usefulness of any information, apparatus, product or process disclosed, or represents that its use would not infringe privately-owned rights. 


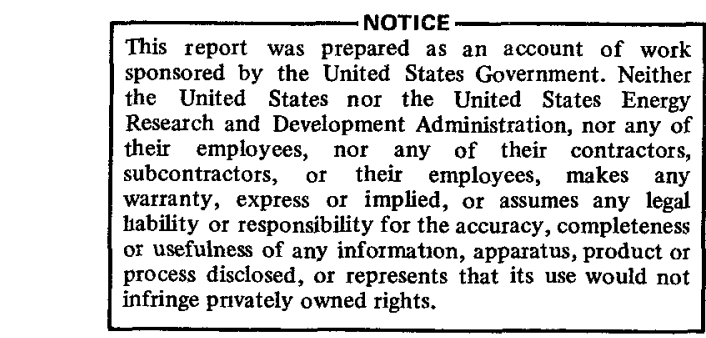

PRELIMINARY REPORT ON LOSS-OF-FLOW CALCULATIONS

FOR THE CRBR DEMONSTRATION PLANT

\section{ABSTRACT}

Loss-of-flow calculations have been performed for the Clinch River Breeder Reactor. Results are preliminary because of inaccuracy in the reactor model, but are not expected to be much different when model corrections are made. A pump coastdown calculation without scram, and very rapid flow decay calculations with and without scram to simulate pipe rupture accidents have been carried out. For a wide range of flow decay rates without scram a mild initial disassembly caused by a few atmospheres fuel vapor pressure occurs. It appears that boiling can be prevented in a double-ended pipe rupture with scram if core flows of about $25 \%$ or more of the initial can be maintained after the rupture, with the required final flow rate sensitive to fuel-clad gap conductance. 


\section{TABLE OF CONTENTS}

\section{Introduction}

II. SAS-3A Mode1 Used

III. Results of Pump Coastdown and Less Extreme Pipe-Rupture Calculations Without Scram

IV. Results of Extreme Pipe Rupture Calculations

V. Summary and Conclusions 
PRELIMINARY REPORT ON LOSS-OF-FLOW CALCULATIONS

FOR THE CRBR DEMONSTRATION PLANT

\section{Introduction}

A number of loss-of-flow (LOF) calculations using the SAS-3A code ${ }^{1}$ have been carried out for the Clinch River Breeder Reactor (CRBR) (2) (Fig. 1). Although the model of the reactor was based on incomplete information and is somewhat inaccurate in several respects, it was considered that conclusions based on the results obtained so far are worth presenting at this time, as they should not be altered in any significant way by use of a more accurate representation. Calculations on a corrected model are under way, and the results will be presented in due course.

Results are presented for LOF calculations for the beginning-of-1ife (BOL) state. A pump coastdown case without scram is presented, and results are also presented for pipe rupture accidents simulated by very rapid flow decay with and without scram.

Details of the methods of calculating reactivity coefficients and power distributions are given in a report by Kalimullah. ${ }^{3}$

\section{SAS-3A Mode1 Used}

The core of the Beginning-of-Life (BOL) CRBR has been represented by ten SAS channels as shown in Table I. Subassembly Rings 2-7 comprise the inner enrichment region and Rings 8-9 the outer. Ring 1 is a control rod position, and there are also control and safety rods in Rings 4 and 7 (see Fig. 1).

For the BOL core a burnup of ten days was assumed. Because a negligible influence of fission gas on fuel dispersal was assumed, the burnup of 
the fuel actually is of little significance in the present calculations except for its effect on reactivity coefficients and power distributions, and, as discussed in Section IV, on the fuel-clad gap thermal conductance. The power distribution used has a radial distribution somewhat steeper than that appropriate for the BOL core. It is about right for the beginning-ofequilibrium cycle (BOEC) core, except that the power normalization for Channel 7, which represents the higher-powered subassemblies at the inner edge of the outer core, is about $10 \%$ lower than would be appropriate for the BOEC case. A flatter radial power distribution would lead to more coherence in sodium voiding, clad motion, and fue1 motion, but since lumping many subassemblies together in channels tends to give too much coherence in the first place, this lack of coherence for the BOL core is probably not an important deficiency in the present results.

The steady-state mass velocity $G_{0}$ used in the SAS calculations is based on a sodium flow area of $37.2 \mathrm{~cm}^{2}$, which corresponds to the flow area in each pin cell multiplied by the 217 pins in the subassembly. This area is slightly less than that which would be obtained by subtracting the total pin and wire wrap cross-sectional area from the cross sectional area inside the subassembly can because of extra space around the edge of the pin bundle. The original values of $G_{0}$, given in Table $I$, were selected to give the design temperature rise across the reactor assuming that bypass flow had the same temperature rise as the sodium passing through the fueled subassemblies. The revised values in Table II are based on total subassembly sodium flows given by WARD, (4) except that the revised flow in Channel 1 has been divided by a factor of 1.17 to study the effect of a power-to-flow mismatch of this amount. These reduced flow rates were used for some of the calculations for extreme pipe ruptures described in Section IV. 
SAS currently does not provide for any way to represent a pipe rupture accident except for a simulation by a very rapid rate of flow loss through the core, obtained by specification of the fractional decrease of pump head $\Delta \mathrm{P}$ in the primary 10op. This rate of flow loss must be assumed arbitrarily as there is no way at present to calculate it with SAS. Flow decay in SAS can be accomplished in either of two ways. One way is to specify parameters in the equation giving the decay of pump head $\Delta P$ with time $t$ :

$$
\Delta \mathrm{P} / \Delta \mathrm{P}_{\mathrm{O}}=\exp \left(-\mathrm{PDEC} * \mathrm{t}-\mathrm{PDEC} 1 * \mathrm{t}^{2}-\mathrm{PDEC} 2 * \mathrm{t}^{3}\right)
$$

where the coefficients PDEC, PDEC1, and PDEC2 are given in Table III for the cases calculated. Alternatively, flow decay may be specified by providing a table of $\Delta \mathrm{P} / \Delta \mathrm{P}_{\mathrm{O}}$ as a function of time. The latter method was found to be convenient for the extreme pipe rupture cases given in Section IV.

In certain of the cases in Section IV in which scram was assumed to occur, it was triggered on attainment of a power-to-flow ratio of 1.15 times that for the steady state. Scram reactivity in these cases was inserted according to Table IV.

III. Results of Pump Coastdown and Less Extreme Pipe Rupture Cases Without $\underline{\text { Scram }}$

In Table $V$ results are given for several LOF calculations without scram for fractional flow decays corresponding to the parameters given in Table III. The resulting fractional reductions in initial flow as a function of time are given in Fig. 2. The Pump Coastdown curve is one that was appropriate for the FFTF, and corresponds to a slower flow decay than that now specified by WARD, (4) labeled "CRBR Pump Coastdown" in Fig. 2. The pipe rupture cases are characterized by the approximate period for flow decay. 
The WARD curve is seen to be intermediate between the Pump Coastdown curve and that for a pipe rupture accident with a flow decay period of about 4.5 sec.

For the $1.5 \mathrm{sec}$ pipe rupture case three different options in the code were used. In two of these the sodium liquid film was assumed to remain static after boiling voids were formed, and in the third the film motion model ${ }^{5}$ was used. In this model the sodium film moves under the force of gravity and of vapor friction. This motion tends to lead to clad dryout earlier than would otherwise occur. To simulate this effect with the static film model, the film is assumed to disappear when it is reduced by evaporation to two thirds of its original thickness (assumed to be $0.013 \mathrm{~cm}$ ). In the "2-phase" option, also used in the Pump Coastdown and $4.5 \mathrm{sec}$ Pipe Rupture cases, the sodium vapor friction factor was increased by a multiplier which depends on the thickness of the film on the clad and on the structure (subassembly cans and wire wrap). This multiplier is selected by setting decimal input location 634 in SAS equal to 1.0 , while setting this value equal to 0.0 causes the multiplier to be 1.0 . The multiplier is intended to represent the effect of waves or instabilities in the film, which tend to increase the friction. However, because of the way the structure is treated in SAS, in the static film case a thick film (up to $20.030 \mathrm{~cm}$ ) tends to build up on the structure, and this film greatly increases the vapor friction factor through the multiplier. ${ }^{6}$ This has the result of considerably reducing the rate of vapor flow. In the film motion case, on the other hand, this film on the structure tends to be swept away by the action of the vapor. G. Hoppner ${ }^{6}$ has suggested that this reduction in structure film thickness and therefore increase in vapor velocity in the film motion case is at least 
partly responsible for the greater oscillations of the vapor-liquid interfaces, and increased rewetting of the clad after dryout in the film motion case (Fig. 3) compared to the static film case (Fig. 4). In order to test this hypothesis, in the "1-phase" case the multiplier was set equal to 1.0 , with results for Channel 2 in this instance given in Fig. 5 . In this figure the vertical bars represent the extent of voiding, the cross-hatched areas correspond to film dryout, and blank areas at the right represent regions of clad motion. It is seen that there is somewhat more oscillation of the interfaces and rewetting of the clad in the "1-phase" case than in the "2phase" one, although the pattern is considerably different from that of the film-motion case.

There is enough rewetting of the dried-out clad in both the 1-phase and film motion cases to keep it cooler relative to the fuel than in the 2phase case. This has the result of suppressing clad motion in the SAS calculation because fuel slumping is triggered (on $50 \%$ fuel melt fraction in this case) before clad melting is complete, and the option in SAS of not allowing fuel slumping to occur before completion of clad melting was selected. Under these conditions slumping begins when clad melting is complete, and clad motion is suppressed, the reasonable assumption being made that clad will become mixed with fuel under these conditions. What seems unreasonable in the modeling is that if clad melting is complete before slumping is triggered and clad motion starts, there is no provision for mixing clad with fuel when slumping is subsequently triggered. The result of this is that there is no cladding reactivity addition in the one case and a considerable ramp rate in the other (Table VI) for a relatively small difference in cooling of the clad, which seems unreasonable physically. 
The steady-state relative power-to-flow ratio, given in Table $I$, is near1y the same for al1 ten channels, but there is a spread in boiling time under transient conditions corresponding to the greater heat-transfer rates for the higher-powered channels. In a more accurate model of the CRBR Channel 7 would start boiling at a time closer to that for the hotter fuel in the inner core, with clad motion and with fuel motion in more cases a possibility. It is seen from the results in Table $V$ that the reactor power stays relatively close to normal through most of the voiding process, the sodium void reactivity being sufficiently balanced by the Doppler effect to keep the net reactivity below prompt critical. Increases in reactor power to 100 or more times normal occur only when clad motion reactivity is added. The effect of variations in reactivity coefficients on this result will be studied in future work, but it does not seem likely that maximum fuel temperatures in an initial disassembly would vary much from those given in Table VI with reasonable alterations of reactivity coefficients.

It should be noted that no axial expansion feedback has been taken into account in these calculations. Some such feedback is likely to occur in the early stages of a LOF accident and will make the attainment of prompt criticality with sodium voiding more difficult than is indicated here.

The ramp rates at disassembly given in Table VI are moderate even with the effect of clad motion. The exact values are not very significant as they vary somewhat over power peaks because of flucuations in clad motion and sodium voiding, mainly the former. Clad motion reactivity effects are due mainly to the levitation of clad upward at velocities up to $1000 \mathrm{~cm} / \mathrm{sec}$ by the action of sodium vapor. Since the calculation of this vapor velocity is uncertain, particularly when fuel slumping has occurred, and since some 
mixing of clad and molten fuel is 1ikely to occur that is not taken into account in the model, the clad motion ramp rates are of questionable validity, but probably represent an upper limit. The deficiencies of the model as applied to the Demo plant and the need to start over and treat fuel, clad, and sodium vapor motion together in a consistent way is well recognized by the RAS division of ANL. However, this is a problem of great complexity, and it may be that the results of a more accurate model would not be greatly different, at least with regard to predicting the further course of events after the first disassembly at which the SAS calculation now stops.

It is seen in Table VI that in the Film-Motion and 1-phase Static Film cases disassembly occurs with the fuel only at its melting point as a result of levitation by sodium vapor. This occurs in these cases and not in the others as a result of the selection of options and input data and the models in SAS and is explained as follows. ${ }^{7}$ Levitation occurs when the sodiumfuel friction factor QSODUM (Dec. input locations 133-142) has some finite value. This factor is usually set equal to 0.0 when the clad motion option is specified as a conservative assumption because of the possibility of blockage of sodium vapor flow by frozen clad even though the clad motion model may not specifically calculate such a blockage. When no clad motion is specified, a value of about 300.0 is normally input for QSODUM, even though there is a question about whether or not sodium vapor might bypass molten fuel without ejecting it from the core. If clad motion is specified in the input but is suppressed because slumping is triggered before clad melting is complete, a value of 300.0 is supplied for QSODUM by the code. Clad is also assumed to be homogenized with the molten fuel, which involves calculation of the variable FESSR, the grams of steel per gram of fuel to be 
mixed in. FESSR can be specified in the input (Dec. locations 153-162) but is normally set equal to 0.0 if clad motion is expected as otherwise the reactivity effect of the same steel is likely to get counted twice -- once as homogenized with the fuel and once as moving clad. This is possible because there is no connection in the code between clad motion and fuel slumping, except that the fuel pressure enters into the equation of motion of c1ad segments.

It is thus seen that from the options selected in the code and from the properties of the models a considerable difference in shutdown characteristics is possible, even though the difference in physical behavior implied by the various clad film options is rather minor.

While the film motion model yields a considerably different description of the course of sodium voiding and film motion, including rewetting of dried-out clad, the final results do not appear greatly different from the static film results. Since the film motion model takes two or three times as long to run as the static film option, it seems that the latter has a useful role to play in accident calculations.

It seems likely that if shutdown occurs from fuel vapor pressure the final maximum fuel temperature is not going to be far from the range $4000^{\circ}-$ $4500^{\circ} \mathrm{C}$, which is what is needed to generate a few atmospheres fuel vapor pressure, for ramp rates produced by the processes considered here so far. This will be true regardless of input parameters and model details. Not much pressure is required because there is really no resistance to motion until blockages above and below the core from frozen clad and fuel are encountered. These are far enough away that sufficient fuel can move axially (no radial motion is considered in SLUMPY ${ }^{(1)}$ ) away from the center of the 
core to produce shutdown. Lower fuel temperatures are possible if fuel can be moved by other means such as by sodium vapor entrainment or by fission product vapor pressure. Substantially higher fuel temperature in a first disassembly would seem to require a different kind of reactivity effect such as one that might arise from some autocatalytic process.

A possible source of such a reactivity effect, not considered up to this point, is fuel motion or sodium voiding in channels in which liquid sodium is still present and clad is intact as disassembly conditions are approached, but in which a considerable fraction of the fuel is molten. This is seen in Table VI to be the case for the outer channels 6,8 , 9 , and 10. Bursting of clad by fission gas pressure or by expansion of fuel against the clad, with subsequent fuel motion and additional sodium voiding is practically a certainty under these conditions. However, the Fue1-Coolant Interaction (FCI) module of SAS, ${ }^{(1)}$ which calculates such effects, had to be turned off in the present series of calculations, because its use in a channel in which sodium boiling is occurring is not permitted in the current version of the code. What reactivity effects would actually occur is a matter of great uncertainty, because of uncertainties in calculation of fuel dynamics, of clad failure, and of the fuel-coolant interaction. Other calculations have shown that if clad failure occurs above the midplane, as it is likely to because the temperature is higher and the clad therefore weaker, a considerable negative reactivity effect occurs from molten fuel inside the pin moving on the average away from the center of the core, and out into the coolant channel. If the clad failure point is at the center of the core, on the other hand, the reverse is true: fuel moves within the pin on the average toward the center of the core, giving a large positive 
reactivity effect. Failure at the center of the core for pins operating at relatively low powers has been calculated ${ }^{8}$ using a fallure criterion based on transmission of fission gas pressure from a pin "cavity" region defined by the fuel solidus temperature through strengthless fuel to the clad. ${ }^{9}$ This result was ascribed ${ }^{8}$ to the fact that for such lower-power pins the cavity will tend to be only in the vicinity of the center of the core.

It seems that judgment should be reserved on whether or not any significant positive reactivity effect is possible from failure of pins in the outer part of the core in a LOF accident. There may be enough inco- . herence in clad failure locations and tendency to fail in the upper part of the core to eliminate positive effects. On the other hand, a relatively. small positive effect coming in rapidly when the reactor is already at prompt critical could be extremely serious. One positive effect that can be introduced by SAS-FCI and is spurious ${ }^{10}$ is one that can occur when the region of sodium voiding by an FCI is in the upper part of the channel. Because SAS-FCI calculates fuel velocities by interpolating between the velocities of the upper and lower gas-liquid interfaces, the interpolated fuel velocity at the point of clad rupture can be downward for a rupture in the upper part of the core, giving a strong positive reactivity effect. Comparison with the more exact PLUTO code indicated that this result had no physical reality. 10

IV. Results of Extreme Pipe Rupture Calculations

Flow reduction in these cases was achieved by using a tabular input of $\Delta \mathrm{P} / \Delta \mathrm{P}_{\mathrm{o}}$ as a function of time. In the tables, $\Delta \mathrm{P} / \Delta \mathrm{P}_{\mathrm{o}}$ was equal to 1.0 at time $t=0$, and held constant from $t=0.004$ at various final values ranging 
from 0.01 to 0.1 . These ratios labelled simply $\Delta \mathrm{P}$, by which they will be referred to henceforth, appear as parameters in Fig. 6-8 and in Tables VII and VIII; while convenient for parameterizing the rate of flow reduction they have no actual physical significance as far as a pipe rupture accident is concerned.

The flow reductions produced with these parameters are given in Fig. 6 . The flow is seen to level off for $\Delta \mathrm{P}=0.02$ to $\Delta \mathrm{P}=0.10$ after several tenths of a second to fractions of the initial flow ranging from 0.066 to 0.28 . For $\Delta \mathrm{P}=0.01$ the flow goes to zero at about $0.6 \mathrm{sec}$ and even reverses slightly because of the effect of the gravity head.

Calculations for pipe rupture accidents assuming no scram were carried out to a time of about $1.0 \mathrm{sec}$ for various $\Delta \mathrm{P}^{\prime} \mathrm{s}$ and for values of channel mass velocity $G_{O}$. Results at $1.0 \mathrm{sec}$ are given in Table VIII for Channels $I$ and 2. The original $G_{0}$ 's are those given in Table $I$; the reduced ones are given in Table II. Channel 2 is the hottest channel for the original $G_{0}$ 's. For the reduced $G_{O}$ 's the rate of coolant heating is about the same for Channels 1 and 2; the additional reduction of $17 \%$ in $G_{0}$ for Channe1 1 about balances the $6.5 \%$ higher power in Channe1 2 as far as transient heating of the coolant is concerned.

It is seen that no boiling will occur for about 1.3 seconds regardless of the way the flow decays simply because of the fuel pin time constants. There also does not seem to be great sensitivity to variation in the steadystate power-to-flow ratio. The power stays near normal before boiling in these very rapid flow decay cases. In the slower flow decays in Table V 
the power falls to as low as 0.8 of normal in the preboiling period. The reason for this difference is that in the very rapid flow decay cases the reactor regions above the core do not have time to heat up, and so lower the temperature of the coolant as it traverses these regions. This eliminates a negative contribution to the sodium density coefficient and causes the power to be higher than for the slower flow decay cases.

The very rapid flow decay cases without scram have not been pursued to the disassembly phase. If they were the final results should be similar to those in Table VI. Because a massive pipe rupture accident is generally regarded as being a very low probability event, it seems most reasonable to assume that if it did occur, scram would be operative. Accordingly, the effect of introducing scram reactivity according to Table IV was studied, with results given in Fig. 7 and 8 . The scram table used in these figures is referred to as delayed scram; it is delayed by $0.2 \mathrm{sec}$ over that used originally, which seems to be reasonably achievable, to add conservatism and study the sensitivity of the accident to the delay time.

A problem in these calculations not recognized until after they were completed is that a deficiency in the primary loop module being used caused the outlet pressure to be set at 2.1 atm instead of the 1.45 atm specified in the input. This had the effect of raising the saturation temperature at the point of maximum coolant temperature from about $940^{\circ} \mathrm{C}$ to about $980^{\circ} \mathrm{C}$, giving a boiling temperature with $10^{\circ} \mathrm{C}$ superheat of $990^{\circ} \mathrm{C}$. Even the lower pressure might be too high under certain conditions in a severe pipe rupture accident, but the lower limit in any case for boiling temperature would be $890^{\circ} \mathrm{C}, 10^{\circ} \mathrm{C}$ above the atmospheric boiling point. The estimated boiling times in Table VIII have been based on a boiling temperature of $950^{\circ} \mathrm{C}$. The higher 
boiling temperature is the one given in Fig. 7 and 8 , and the results in these figures were obtained assuming boiling at $990^{\circ} \mathrm{C}$.

The results in Fig. 7 indicate that boiling does occur in the $\Delta P=0.02$ case with the delayed scram, and according to the results in Table VIII, also with the original scram, although the calculation was not carried quite this far in this case. Although the decay power level of $6.4 \%$ of normal about matches the final flow rate of $6.6 \%$ of the initial flow, the heat stored in the pin is sufficient to produce coolant boiling. The fuel and clad temperatures at the end of the calculation are low, however. The clad temperature, not shown, is essentially at the coolant boiling temperature and is thus well below the clad melting temperature of $1371^{\circ} \mathrm{C}$. What would happen at later times depends on whether or not a coolant flow of a few percent of the initial one could be reestablished in the channel, as otherwise the decay power would eventually cause fuel and clad melting. Because of the low power there would be a large amount of incoherence in this process, however, and it is hard to imagine that any significant reactivity ramp rate could be produced. It does not appear profitable to pursue this calculation any further with SAS until some capability for dealing explicitly with pipe rupture accidents is developed.

The case of $\Delta P=0.01$, in which coolant flow drops to zero in $0.6 \mathrm{sec}$, has not been calculated with scram, but from comparison with other cases without scram in Table VII it seems likely that clad melting would not occur for several seconds and that fuel melting would require many seconds.

For $\Delta \mathrm{P}=0.03$, in which the coolant flow levels out at $11 \%$ of the initial flow, a coolant boiling temperature of $950^{\circ} \mathrm{C}$ is almost attained in channel 1 , 
while $920^{\circ} \mathrm{C}$ is attained in Channel 2, as shown in Fig. 8. This flow is at about the lower limit of that necessary to prevent boiling with scram for the assumptions in the calculations. It appears that the exact shape of the flow decay curve is not too important, the percent of initial flow attained after several tenths of a second being most significant.

Changes in the assumptions which would affect the minimum flow to prevent boiling, besides the boiling temperature, are the fuel-clad gap conductance and the power level in the pin. The temperature drop across the gap in the present calculations is about $200^{\circ} \mathrm{C}$. An increase in this temperature difference would increase the amount of heat stored in thy pin and increase the flow necessary to prevent boiling after scram. The gap conductance used in the SAS calculations was $0.002 / \Delta \mathrm{r}$ watts $/ \mathrm{cm}^{2}-{ }^{\circ} \mathrm{C}$, where $\Delta \mathrm{r}$ is the gap in $\mathrm{cm}$, with a maximum value for zero gap specified to be 1.13 . The gap in our calculation was about $0.002 \mathrm{~cm}$, leading to a conductance of about 1.0. From the data supplied by WARD ${ }^{(4)}$ the gap for fresh fuel is actually about $0.007 \mathrm{~cm}$, which according to the LIFE-II heat transfer correlation used by WARD ${ }^{(4)}$ gives a gap conductance of 0.51 . With irradiated fuel the LIFE-II correlation indicates a sharp drop in gap conductivity when helium is replaced by fission gas, but the gap is smaller because of fuel swelling. With zero gap and $100 \%$ fission gas bond the correlation gives a conductance of 0.97 ; with a gap of $0.0006 \mathrm{~cm}$ the conductance is 0.41 , and with $0.006 \mathrm{~cm}$ it is 0.21 . While it is hard to tell in practice what the right combination of gap width and bond gas composition is for irradiated fuel, a conductance of about 0.4 seems to be reasonably conservative in the light of the LIFE-II correlation and of results from the water-reactors program. (11) This would give a temperature drop across the gap of $500^{\circ} \mathrm{C}$ in the steady state and raise our fuel temperatures by $300^{\circ} \mathrm{C}$. 
We have evaluated the effect of a decrease in gap conductance to 0.4 watts $/ \mathrm{cm}^{2}-\mathrm{sec}$. The power level in Channel 2 was also increased by a factor of 1.05 in these calculations as it appears that local hot spots might have a power this high. It was found that boiling occurs in this case for $\Delta \mathrm{P}=$ 0.05 (final flow $18 \%$ of original) but does not for $\Delta \mathrm{P}=0.10$ (final flow $28 \%$ of origina1). This extreme sensitivity of boiling condition to gap conductance was not recognized until the work reported in this memo was substantially complete.

The effort of an increase in the power level in Channel 2 by a factor of 1.2 relative to the original power was investigated for the case $\Delta \mathrm{P}=0.03$ for the original gap conductance. It was found that boiling would occur at 1.26 seconds under these conditions. However, this corresponds to a power of 1.57 times the average, or an average pin power of $11 \mathrm{kw} / \mathrm{ft}$, which is much higher than is likely to be encountered in the CRBR.

No evaluation has been made here of what sort of pipe rupture accident. would correspond to a given rate of flow decay. In the PDP demo plant studies of several years ago final flows of 20 to $50 \%$ of the initial were calculated even for a double-ended pipe rupture at the inlet nozzle. Obviously this depends on the design of the plant.

Little further studies of pipe rupture accidents in the CRBR beyond those reported here are planned until some explicit representation of pipe rupture accidents becomes available. The inaccuracy in representation of the CRBR is irrelevant for the purposes of Section IV, so that an extensive series of calculations with a corrected mode1 seems unnecessary. 


\section{Summary and Conclusions}

Loss-of-flow calculations without scram have been performed for a wide variation in rates of flow decay, with results not too different. Rather mild initial disassemblies are predicted, with maximum fuel temperatures in the range $4000-4500^{\circ} \mathrm{C}$ attained, corresponding to a few atmospheres fuel vapor pressure. Moderate ramp rates from sodium voiding and clad motion totaling up to about $\$ 25 / \mathrm{sec}$ are calculated, with the main contribution coming from clad motion. Positive reactivity from fuel slumping is insignificant; shutdown is achieved by the motion of fuel out of the core.

It does not seem likely that these conclusions will be changed much by reasonabie alterations in input parameters such as reactivity worths. There is some sensitivity to model options and features, with clad motion occurring or not in situations not much different physically. Use of the coolant film motion model makes considerable difference in the detailed course of coolant boiling and clad dryout, but does not seem to make much difference in the final results. Although the fuel and clad motion modules in SAS represent rather impressive achievements, it is indicative of the complexity of the problems involved that SAS is not completely adequate for dealing with the problems of the CRBR. It is recognized by the RAS division of ANL that an integrated approach to the calculation of fuel, clad, and sodium is needed that also takes account to the extent possible of intra-subassembly incoherence is desirable. Some judgment has to be exercised as to how much detail it is worth going into in the initial phase of the calculation, however, as a f:irst disassembly in a LOF accident is likely to be mild in any case for the CRBR. (The effect of more positive reactivity coefficients in a larger reactor has not been evaluated.) The essential problem is in predicting 
the further course of events, not possible at present with SAS. For this one needs such information about the spatial distribution, velocities, and temperatures of the various reactor constituents as might be relevant to a calculation of recriticality and finál disassembly.

The foregoing discussion of LOF accidents needs to be qualified by the observation that large reactivity ramp rates are conceivable from failure of fuel in the outer part of the core, in which the clad might still be intact and in which liquid sodium might still be present. Failure of such fuel could cause large reactivity addition rates from motion of fuel and liquid sodium. This does not seem very likely, but current models are quite inadequate to deal with this situation. It was not possible to calculate such pin failures at all in the present calculations because of the limitations of SAS.

offsetting this possible positive reactivity insertion is the neglect of the negative axial expansion feedback, which is comparable to the Doppler effect and should make disassembly milder than has been calculated here. Study of very rapid flow decay transients presumed to result from double-ended pipe ruptures indicates that if scram occurs boiling of sodium can be prevented if final coolant flow rates of $10 \%$ to $25 \%$, depending on fuel-clad gap conductance, can be maintained after a few tenths of a second. This conclusion does not seem to be sensitive to the details of the flow decay immediately following the pipe rupture. 


\section{References}

1. M. G. Stevenson et a1, "Current Status and Experimental Basis of the SAS LMFBR Accident Analysis Code Systems," Proc. Fast Reactor Safety Meeting, Beverly Hills, Calif., April 2-4, 1974, CONF-740401-P3, pp. 1303-1321.

2. D. R. Riley et al, "Nuclear Design of the Clinch River Breeder Reactor System," Proc. Conf. on Advanced Reactors: Physics, Design, and Economics, Atlanta, Georgia, Sept. 8-11, 1974.

3. Kalimullah, "Preliminary Physics Calculations for the Clinch River Breeder Reactor," RSA-TM-2, Argonne National Laboratory, in preparation.

4. "CRBRP Physics Design, and Physical Properties Data Package," Project Management Corp. Letter, H. E. Bliss to R. P. Denise, July 24, 1974.

5. G. Hoppner and F. E. Dunn, "Sodium Film Model in SAS-2A Voiding," Trans. Am. Nuc1. Soc. 16, 2 (Nov. 1973).

6. G. Hoppner, private communication.

7. W. R. Boh1, private communication.

8. E. T. Rumble, III et al, "Fuel Movement Investigations During LMFBR Overpower Excursions Using a New Mode1," Proc. Fast Reactor Safety Meeting, Bever1y Hills, Calif, April 2-4, 1974, CONF-740401-P3, pp. 1556-1571.

9. L. L. Smith and M. G. Stevenson, "Effect of Reactivity Insertion Rate on Fuel Pin Failure Threshold," Trans. Am. Nucl. Soc. 17, 284 (1973).

10. H. U. Wider et al, "An Improved Analysis of Fuel Motion During an Overpower Excursion," Proc. Fast Reactor Safety Meeting, Bever1y Hills, Calif, April 2-4, 1974, CONF-740401-P3, pp. 1541-1555.

11. D. D. Lanning et al, "Statistical Analysis and Modeling of Gap Conductance Data for Reactor Fuel Rods Containing UO ${ }_{2}$ Pellets," BNWL-1832, August, 1974 . 


\section{Acknowledgment}

W. R. Bohl, T. J. Heames, and G. Hoppner provided valuable advice and assistance in running the SAS-3A code. We are indebted to $\mathrm{K}$. J. Miles and I. T. Hwang for pointing out the importance of gap conductance for coolant boiling in a pipe rupture accident with scram. 


\section{FIGURE CAPTIONS}

Fig. 1 Reactor core cross section for CRBR

Fig. 2 Flow Reduction rates for pump coastdown and for less extreme pipe rupture cases

Fig. 3 Sodium liquid-vapor interface location for 1.5 second pipe rupture accident, film motion option, 2-phase friction factor. Cross-hatched areas represent film dryout. Blank area at right represents clad motion. Dashed line gives sodium voiding reactivity

Fig. 4 Sodium 1iquid-vapor interface location for 1.5 second pipe rupture accident, static film, 2-phase friction factor

Fig. 5 Sodium liquid-vapor interface location for 1.5 second pipe rupture accident, static film, 1-phase friction factor

Fig. 6 Fractional flow reduction rates for extreme pipe rupture. accidents

Fig. 7 Results for extreme pipe rupture accident with delayed scram, $\Delta P=0.02$, reduced $G_{0}$

Fig. 8 Results for extreme pipe rupture accident with delayed scram, $\Delta P=0.03$, reduced $G_{0}$ 
RADIAL REFLECTOR ASSEMBLIES (72) 7 RADIAL RESTRAINT ASSEMBLIES (78)

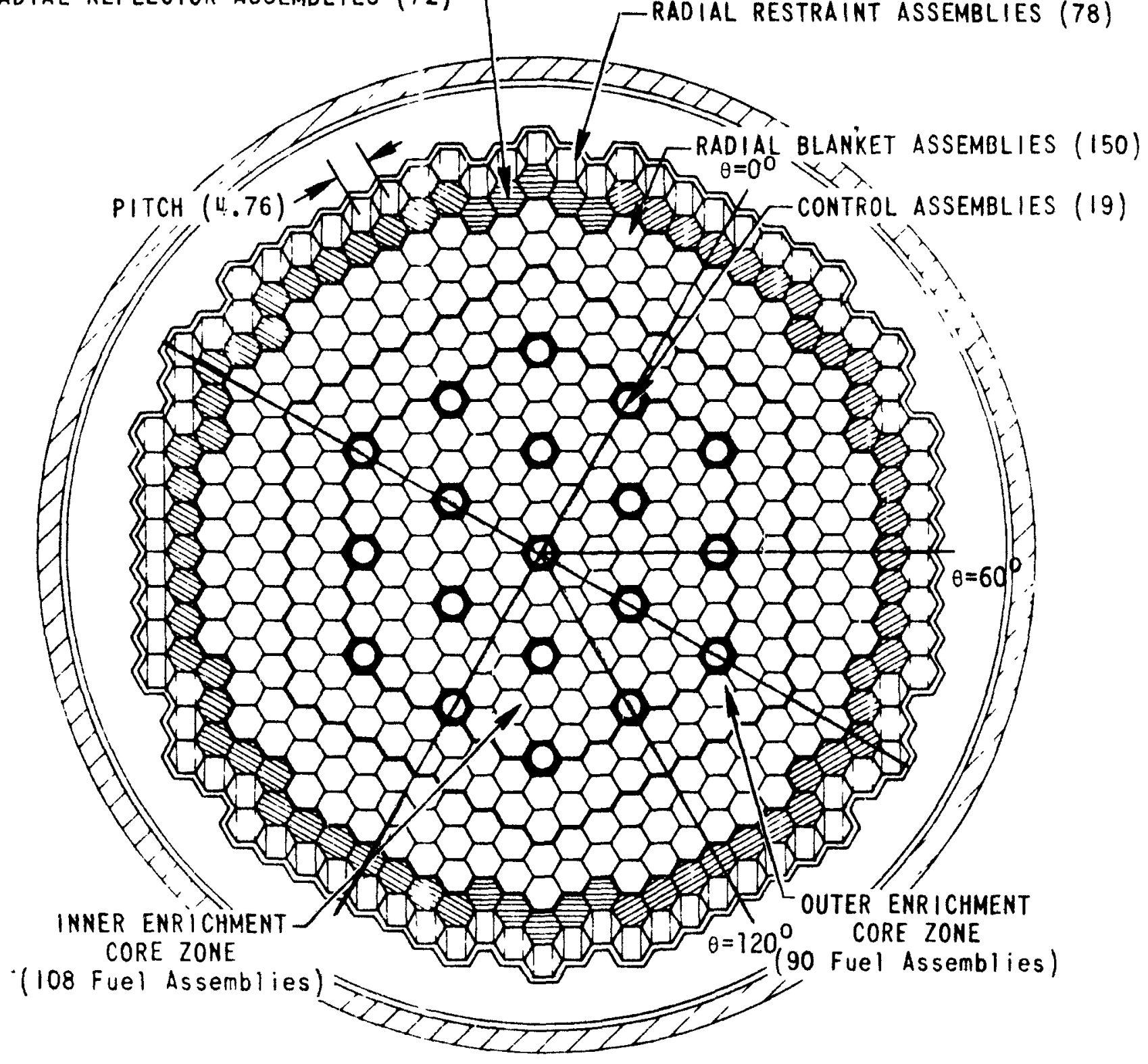

Figure 1. Reactor core cross section for CRBR 


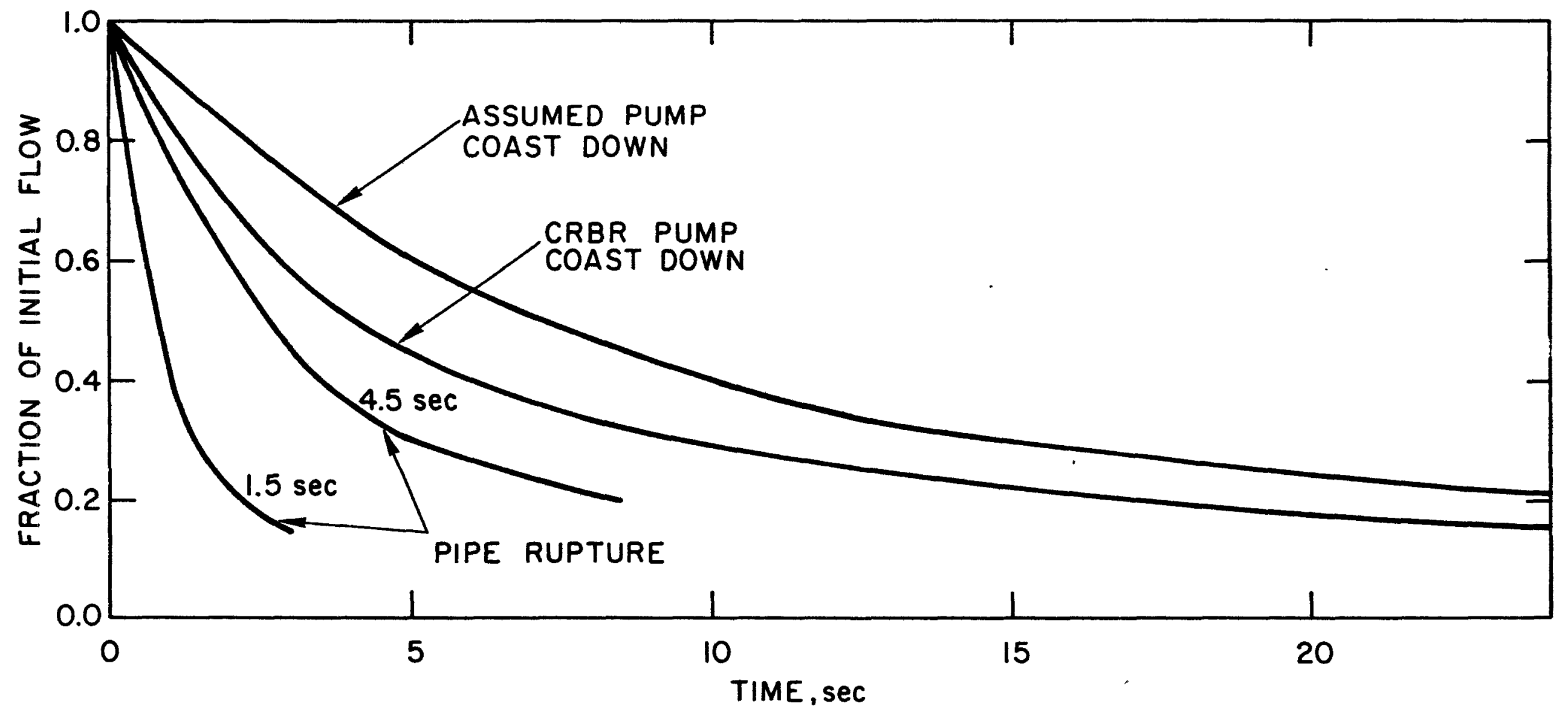

Figure 2. Flow Reduction rates for pump coastdown and for less extreme pipe rupture cases 


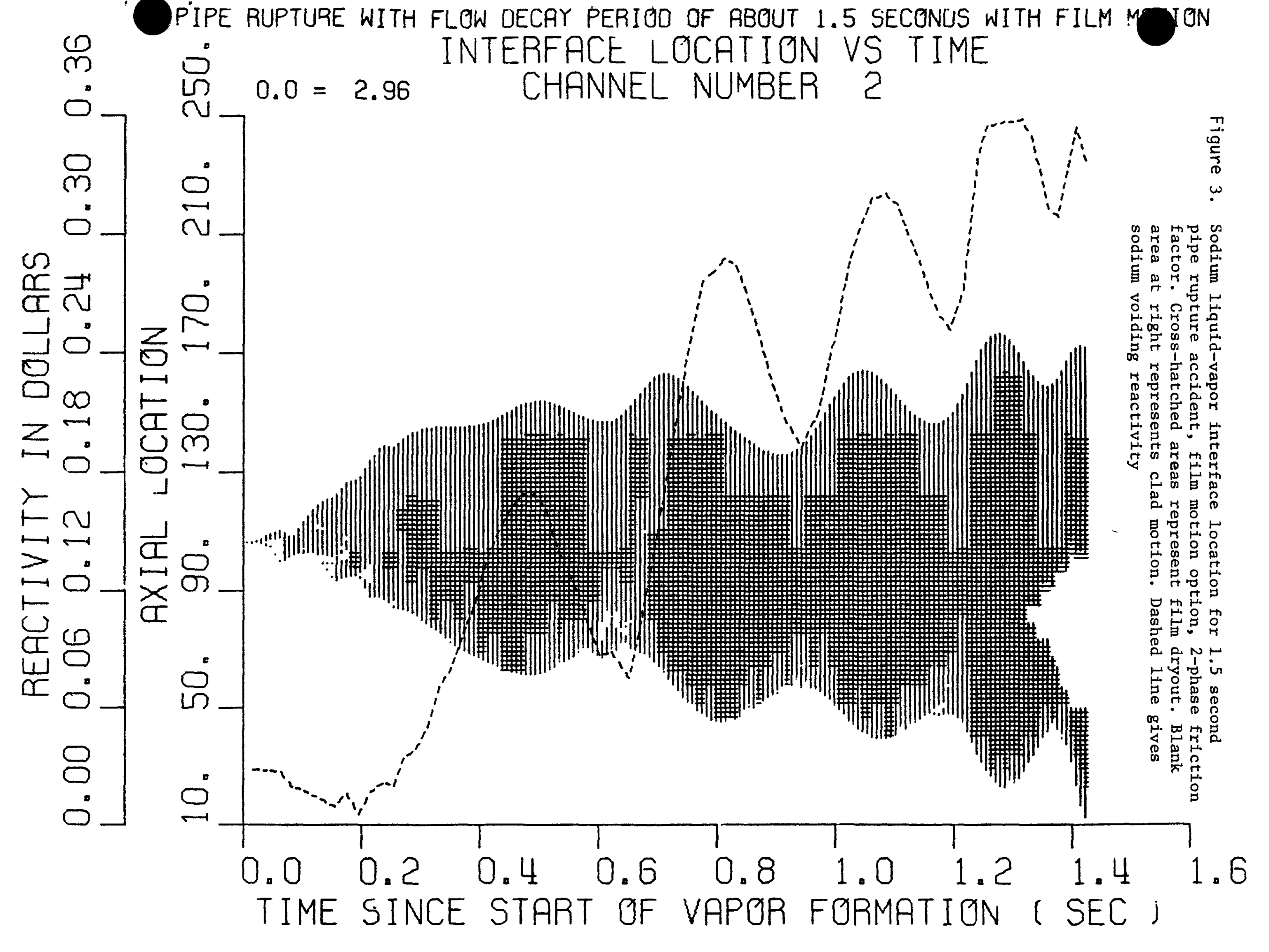




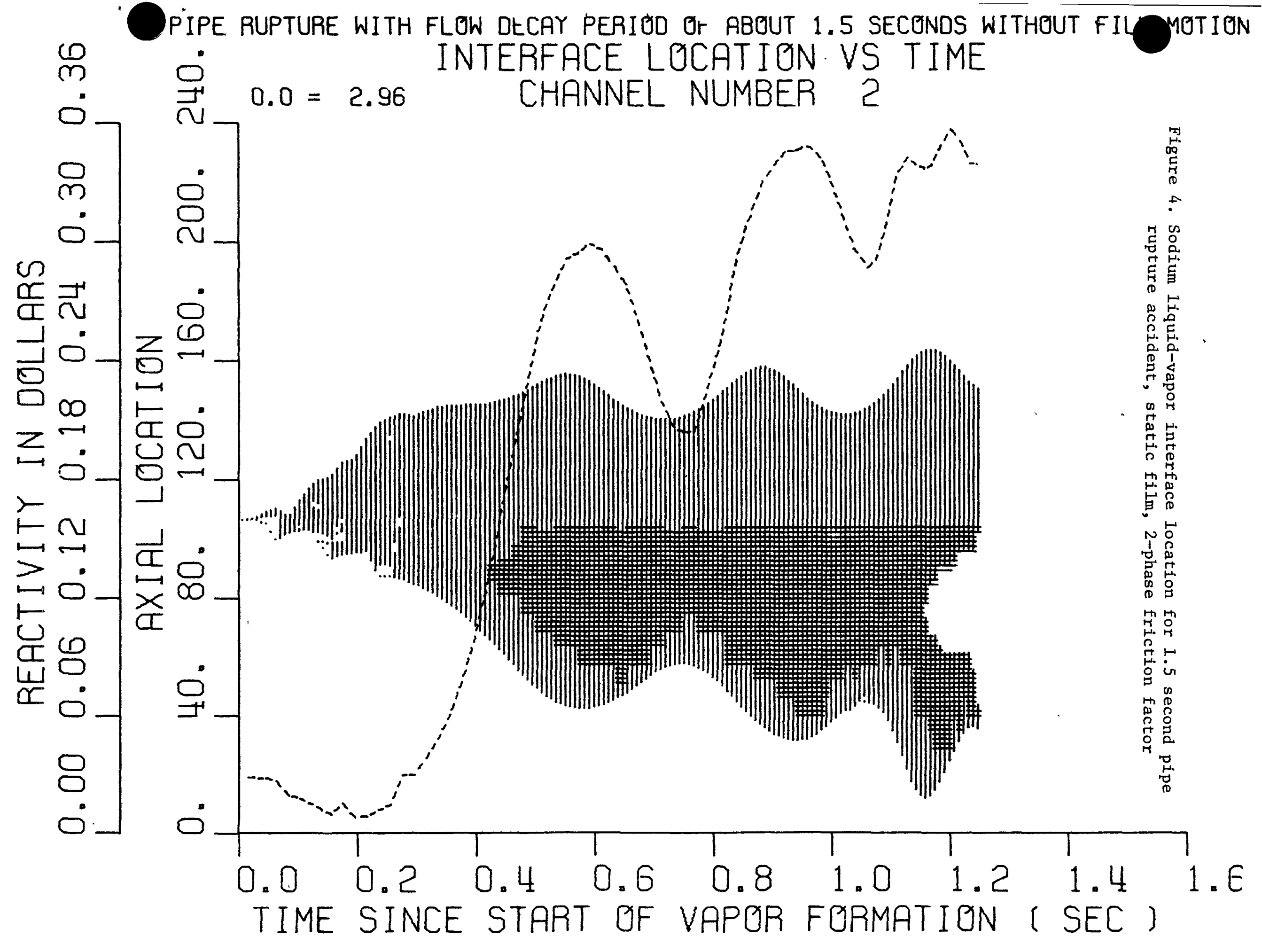




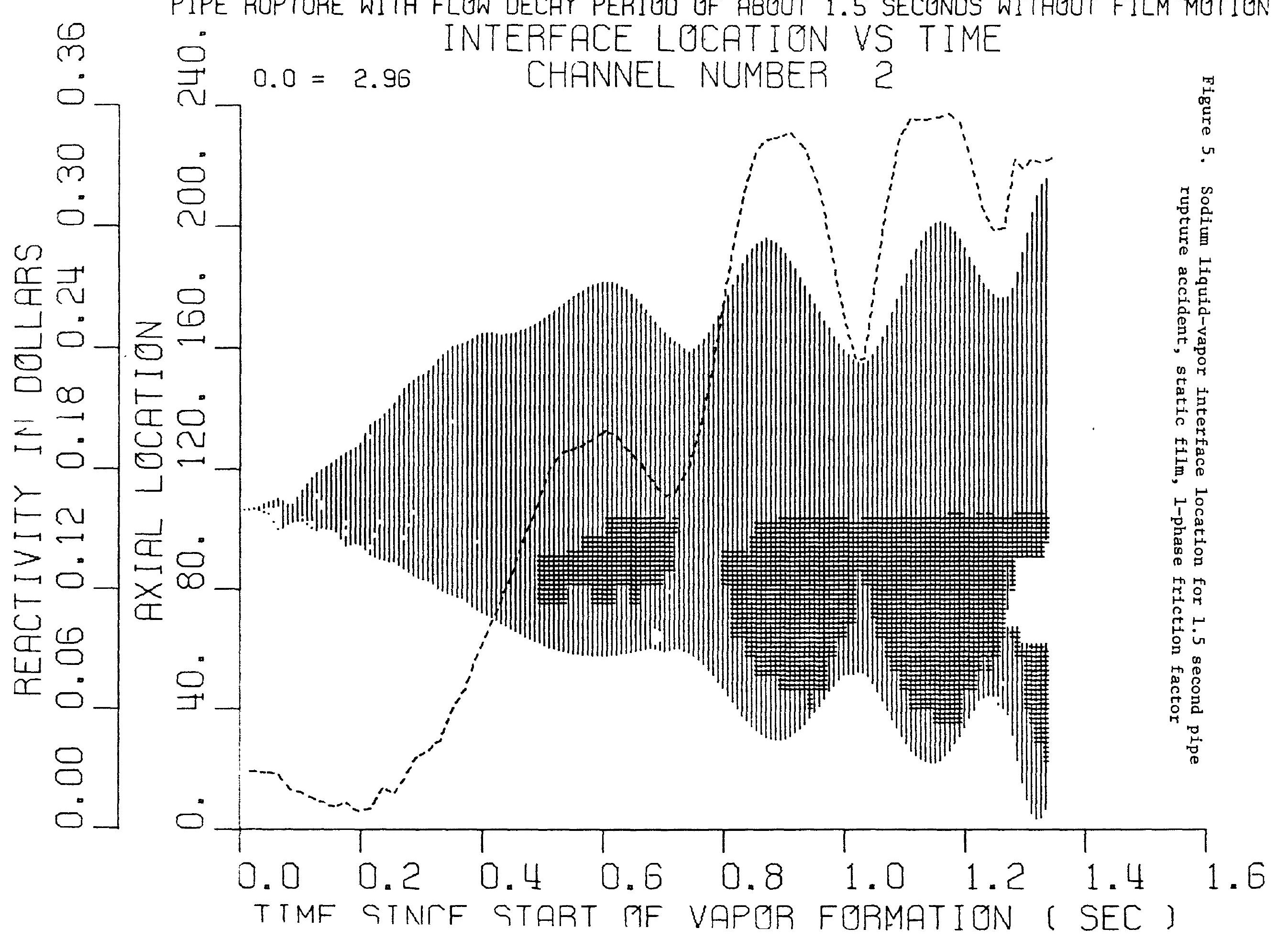




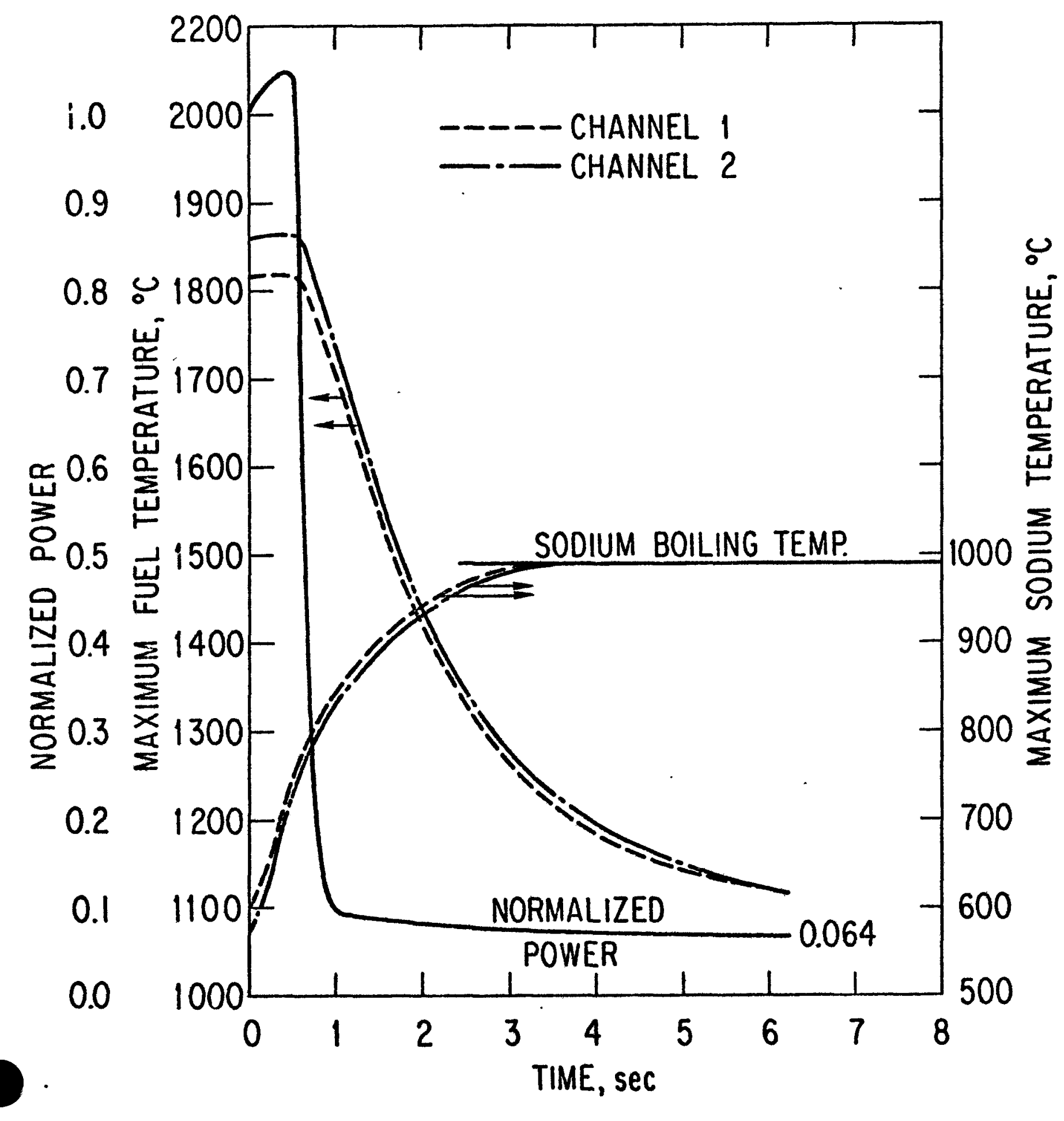

Figure 7. Results for extreme pipe rupture accident with delayed scram, $\Delta P=0.02$, reduced $G_{0}$ 


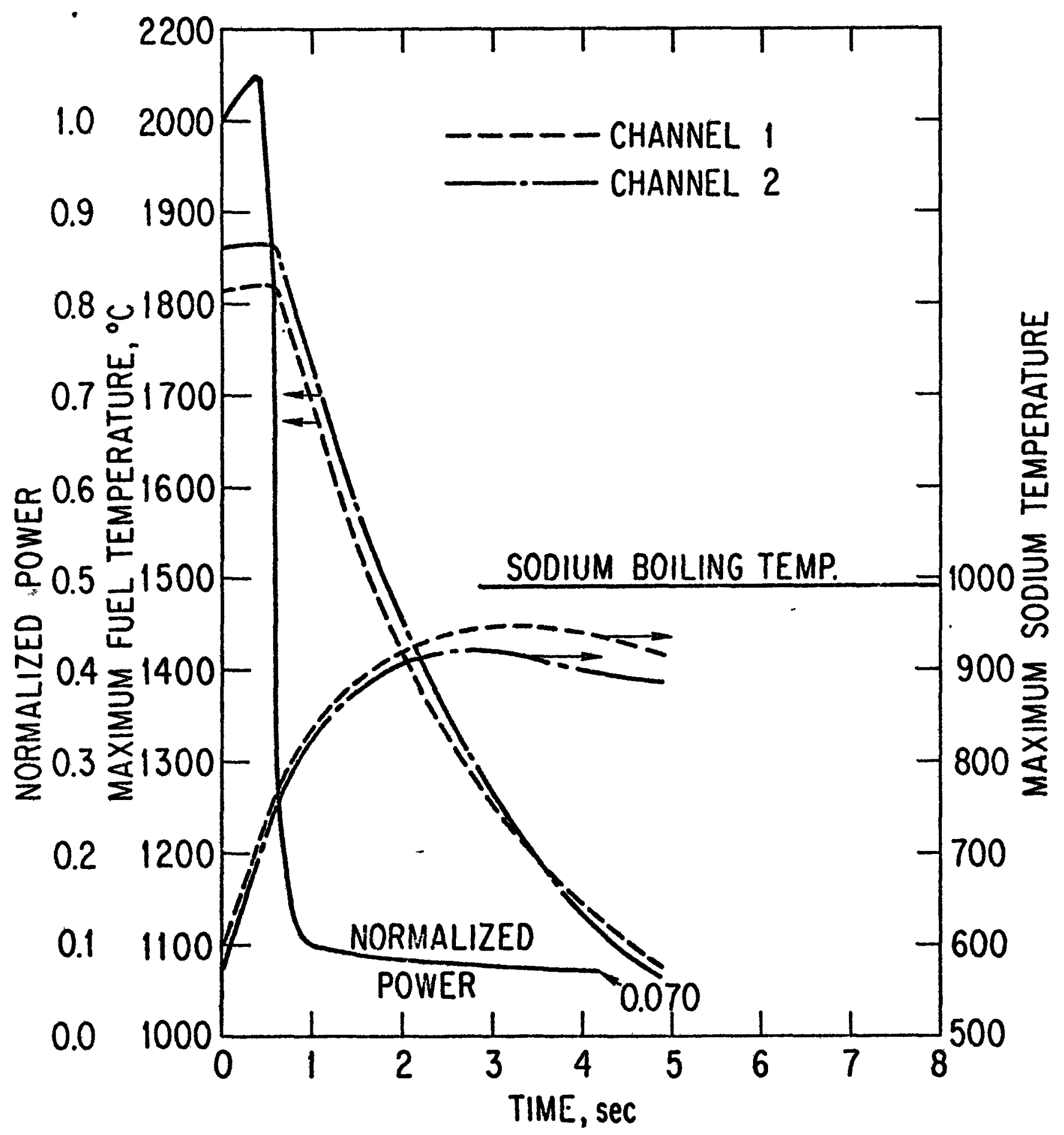

Figure 8. Results for extreme pipe rupture accident with delayed scram, $\Delta P=0.03$, reduced $G_{0}$ 


\section{LIST OF TABLES}

Table I. Assignment of SAS Channels for BOL Demo Plant

Table II. Reduced Coolant Mass Velocities

Table III. Flow Coastdown Parameters

Table IV. Assumed Scram as a Function of Time after Meeting Scram Criterion

Table V. Starting Times for Boiling, Clad Motion, and Fuel Motion in LOF Calculations Without Scram

Table VI. Conditions at Disassembly for LOF Calculations Without Scram

Table VII. Comparison of Pipe Rupture Cases Without Scram at $1.00 \mathrm{sec}$ After Start of Transient

Table VIII. Effect of $0.2 \mathrm{sec}$ Delay in Scram for $\Delta P=0.02$, Reduced $G_{0}$ 's, $2.63 \mathrm{sec}$ After Start of Transient 
Table I. Assignment of SAS Channels for BOL Demo Plant

\begin{tabular}{|c|c|c|c|c|c|c|c|}
\hline SAS & Subassembly & Number of & $\begin{array}{c}\text { Relative } \\
\text { Radial }\end{array}$ & $\begin{array}{l}\text { Original } \\
\text { Coolant } \\
\text { Mass } \\
\text { Velocity G }\end{array}$ & Relatfve & \multicolumn{2}{|c|}{$\mathrm{kw} / \mathrm{ft}$} \\
\hline Channel & Ring & Subassemb1ies & Power & $\mathrm{gms} / \mathrm{cm}^{2} \mathrm{sec}^{\circ(\mathrm{a})}$ & Power/flow & Peak & Ave. \\
\hline 1 & 2 & 6 & 1.244 & 793 & 1.012 & 10.42 & 8.57 \\
\hline 2 & 3 & 12 & 1.313 & 832 & 1.018 & 11.03 & 9.06 \\
\hline 3 & 4 & 12 & 1.300 & 832 & 1.008 & 10.87 & 8.91 \\
\hline 4 & 5 & 24 & 1.202 & 793 & 0.978 & 10.17 & 8.29 \\
\hline 5 & 6 & 30 & 1.050 & 664 & 1.020 & 8.89 & 7.24 \\
\hline 6 & 7 & 24 & 0.881 & 574 & 0.990 & 7.36 & 6.03 \\
\hline 7 & 8 & $24^{(b)}$ & 1.037 & 664 & 1.007 & 8.82 & 7.17 \\
\hline 8 & 8 & 18 & 0.917 & 574 & 1.030 & 7.80 & 6.34 \\
\hline 9 & 9 & 18 & 0.834 & 574 & 0.937 & 7.15 & 5.77 \\
\hline 10 & 9 & 30 & 0.709 & 453 & 1.010 & 6.08 & 4.91 \\
\hline
\end{tabular}

(a) Based on a subassembly sodium flow area of $37.2 \mathrm{~cm}^{2}$.

(b) Because of an input error 21 subassemblies were actually used in Channel 7 in the SAS calculation, giving a reactor with a 195 subassemblies instead of 198 , and creating small errors in the feedback and power normalization. This error was corrected in the runs with reduced coolant mass velocities. 
Table II. Reduced Coolant Mass Velocities

\begin{tabular}{ccc}
$\begin{array}{c}\text { SAS } \\
\text { Channe1 }\end{array}$ & $\begin{array}{c}\text { Revised Go, } \\
\text { gms } / \mathrm{cm}^{2}-\mathrm{sec}\end{array}$ & $\begin{array}{c}\text { Relative } \\
\text { Power/Flow }\end{array}$ \\
\hline 1 & 592 & 1.19 \\
2 & 731 & 1.018 \\
3 & 731 & 1.008 \\
4 & 697 & 0.978 \\
5 & 584 & 1.020 \\
6 & 505 & 0.990 \\
7 & 584 & 1.007 \\
8 & 505 & 1.030 \\
9 & 505 & 0.937 \\
10 & 398 & 1.010 \\
\hline
\end{tabular}


Table III. Flow Coastdown Parameters

Coefficients in

Pump Head Decay

Equations

PDEC (dec. 399)

PDEC1 (dec. 426)

PDEC2 (dec. 427)
Pump

Coast down

0.24

$-0.00643$

0.0000823
Simulated Pipe Ruptures

4.5 Second 1.5 Second

0.7455

5.7455

$-0.05331$

$-0.05331$

0.0015675

0.0015675

In cases in which a tabular input was used for the pump head $\Delta \mathrm{P}, \Delta \mathrm{P}$ expressed as a fraction of the original pump head was reduced at $0.004 \mathrm{sec}$. to values ranging from 0.1 to 0.001 and thereafter held constant. 
Table IV. Assumed Scram Reactivity (a) as a

Function of Time After Meeting

Scram Criterion(b)

Time, Sec.

Reactivity, $\delta \mathrm{k} / \mathrm{k}$
0.0
0.0
0.45
0.0
0.55
$-0.00077$
0.65
$-0.00386$
0.75
0.80
$-0.01564$
0.85
0.90
0.95
1.05
$-0.002992$
$-0.04844$
$-0.06564$
$-0.08342$
$-0.08342$

(a) For delayed scram cases. For original scram table times are 0.2 sec. 1ess.

(b)

The criterion for scram was attainment of a power-to-flow ratio in any channe 1.15 times that for the steady state. 
Table V. Starting Times for Boiling, Clad Motion, and Fuel Motion in Loss-of-Flow Calculations Wi thout Scram

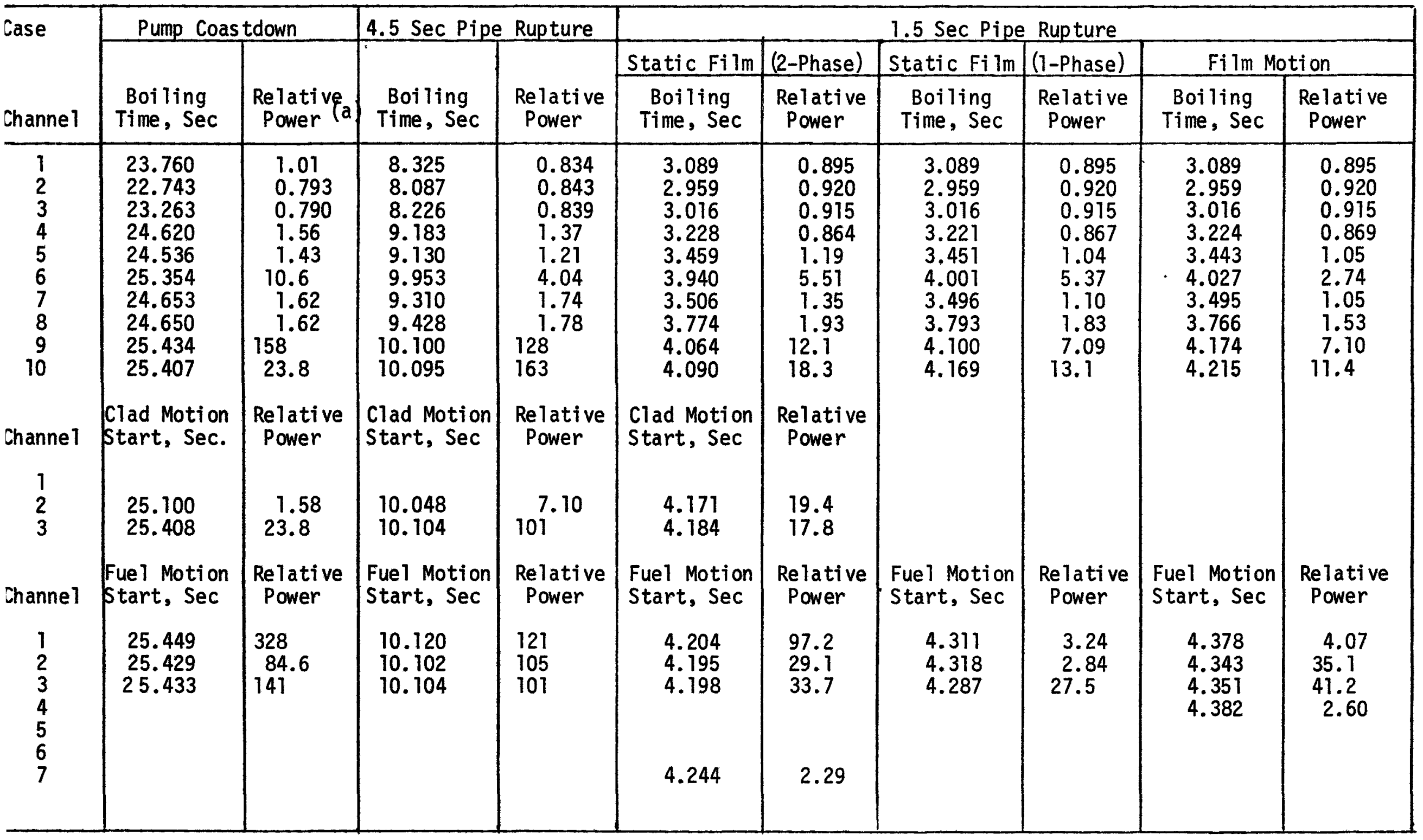

(a) Normalized to normal reactor power. 
Table VI. Conditions at Disassembly for Loss-of-Flow Calculations Without Scram

\begin{tabular}{|c|c|c|c|c|c|}
\hline \multirow[b]{2}{*}{ Case } & \multirow[b]{2}{*}{$\begin{array}{c}\text { Pump } \\
\text { Coastdown }\end{array}$} & \multirow[b]{2}{*}{$\begin{array}{c}4.5 \mathrm{Sec} \\
\text { Pipe Rupture } \\
\end{array}$} & \multicolumn{3}{|c|}{$1.5 \mathrm{Sec}$ Pipe Rupture } \\
\hline & & & $\begin{array}{c}\text { Static Film } \\
\text { 2-Phase } \\
\end{array}$ & $\begin{array}{l}\text { Static Film } \\
\text { 1-Phase }\end{array}$ & $\begin{array}{c}\text { Film } \\
\text { Motion }\end{array}$ \\
\hline $\begin{array}{l}\text { Disassembly } \\
\text { Ramp Rates, } \$ / \mathrm{Sec} \\
\text { Na Voiding } \\
\text { Clad Motion } \\
\text { Fuel Motion }\end{array}$ & $\begin{array}{r}5 \\
22 \\
0\end{array}$ & $\begin{array}{r}10 \\
9 \\
2\end{array}$ & $\begin{array}{r}4 \\
16 \\
2\end{array}$ & $\begin{array}{l}3 \\
--- \\
0\end{array}$ & $\begin{array}{l}3 \\
0 \\
---\end{array}$ \\
\hline Disassembly Time, Sec. & 25.460 & 10.130 & 4.247 & 4.319 & 4.384 \\
\hline Max. Fue 1 Temp, ${ }^{\circ} \mathrm{C}$ & 4534 & 4200 & 4234 & $2767^{(a)}$ & $2767^{(a)}$ \\
\hline $\begin{array}{l}\text { Reactivity Feedback at } \\
\text { Prompt Critical, \$ } \\
\text { Doppler } \\
\text { Na Void } \\
\text { Clad Motion } \\
\text { Fuel Motion } \\
\text { Net }\end{array}$ & $\begin{array}{r}-1.288 \\
1.648 \\
0.629 \\
0.017 \\
0.997\end{array}$ & $\begin{array}{r}-1.143 \\
1.155 \\
0.366 \\
0.026 \\
1.004\end{array}$ & $\begin{array}{r}-1.040 \\
1.831 \\
0.223 \\
0.011 \\
1.025\end{array}$ & \begin{tabular}{l}
-0.948 \\
1.851 \\
\hdashline 0.000 \\
0.903
\end{tabular} & $\begin{array}{l}-0.850 \\
1.790 \\
-0.000 \\
0.940\end{array}$ \\
\hline $\begin{array}{r}\text { Fraction of Core Voided } \\
\text { Channel } 1 \\
2 \\
3 \\
4 \\
5 \\
6 \\
7 \\
8 \\
9 \\
10\end{array}$ & $\begin{array}{l}0.98 \\
0.84 \\
1.00 \\
0.81 \\
0.67 \\
0.08 \\
0.41 \\
0.12 \\
0.01 \\
0.01\end{array}$ & $\begin{array}{l}1.00 \\
1.00 \\
0.79 \\
1.00 \\
0.78 \\
0.15 \\
0.82 \\
0.38 \\
0.08 \\
0.08\end{array}$ & $\begin{array}{l}1.00 \\
1.00 \\
0.83 \\
0.83 \\
1.00 \\
0.61 \\
0.80 \\
0.62 \\
0.41 \\
0.25\end{array}$ & $\begin{array}{l}0.83 \\
1.00 \\
0.78 \\
0.72 \\
0.89 \\
0.42 \\
0.71 \\
0.65 \\
0.25 \\
0.17\end{array}$ & $\begin{array}{l}0.89 \\
1.00 \\
0.79 \\
0.76 \\
0.76 \\
0.56 \\
0.83 \\
0.69 \\
0.35 \\
0.18\end{array}$ \\
\hline $\begin{array}{l}\text { Inner Core } \\
\text { Outer Core }\end{array}$ & $\begin{array}{l}0.64 \\
0.14\end{array}$ & $\begin{array}{l}0.73 \\
0.34\end{array}$ & $\begin{array}{l}0.86 \\
0.50\end{array}$ & $\begin{array}{l}0.80 \\
0.53\end{array}$ & $\begin{array}{l}0.75 \\
0.49\end{array}$ \\
\hline
\end{tabular}

${ }^{(a)}$ Disassembly from sodium vapor entrainment. 
Table VI (cont'd)

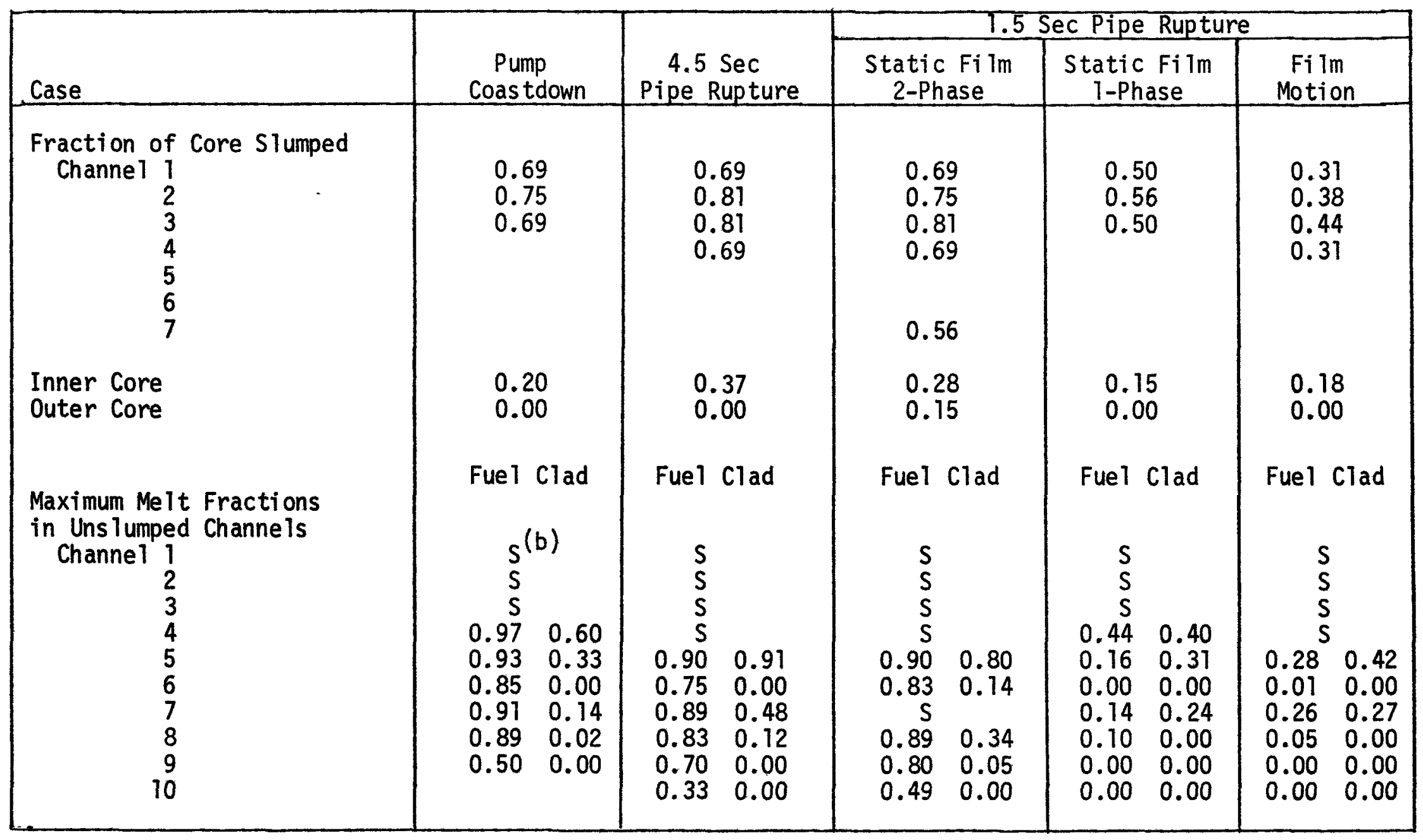

(b) Slumping has already occurred in Channels for which " $S$ " is entered. 
Table VII. Comparison of Pipe-Rupture Cases Without Scram at $1.00 \mathrm{Sec}$ After Start of Transient

\begin{tabular}{|c|c|c|c|c|c|c|c|c|c|c|c|c|c|c|c|c|c|}
\hline \multirow[b]{3}{*}{$\Delta P$} & \multirow{3}{*}{$G_{0}^{\prime} s$} & \multirow{3}{*}{$\begin{array}{l}\text { Norm. } \\
\text { Power }\end{array}$} & \multirow{3}{*}{$\begin{array}{c}\text { Energy, } \\
\text { Ful1- } \\
\text { Power } \\
\text { Seconds }\end{array}$} & \multicolumn{7}{|c|}{ Channel 1} & \multicolumn{7}{|c|}{ Channel 2} \\
\hline & & & & $\operatorname{Max}$ & Temp &.${ }^{\circ} \mathrm{C}$ & $\begin{array}{l}\mathrm{Ra} \\
\mathrm{Ch}\end{array}$ & of ? & $\begin{array}{l}\text { emp. } \\
\mathrm{C} / \mathrm{Sec}\end{array}$ & $\begin{array}{l}\text { Extrapolated } \\
\text { Boiling Time, }\end{array}$ & Max & . Temp &.${ }^{\circ} \mathrm{C}$ & $\begin{array}{l}\text { Rat } \\
\text { Ch: }\end{array}$ & of & $\begin{array}{l}\text { Temp. } \\
{ }^{\circ} \mathrm{C} / \mathrm{Sec}\end{array}$ & $\begin{array}{l}\text { Extrapolated } \\
\text { Boiling Time, }\end{array}$ \\
\hline & & & & Fue1 & Clad & Coolant & Euel & $\mathrm{Clad}$ & Coolant & Sec & Fue1 & Clad & Coolant & Euel & Clad & Coolant & Sec \\
\hline 0.01 & Original & 1.036 & 1.042 & 1821 & 866 & 854 & 70 & 290 & 290 & 1.33 & 1885 & 889 & 875 & 80 & 310 & 300 & 1.25 \\
\hline 0.02 & Reduced & 1.036 & 1.032 & 1850 & 891 & 880 & 70 & 270 & 270 & 1.26 & 1897 & 880 & 877 & 70 & 290 & 290 & 1.25 \\
\hline 0.03 & Reduced & 1.023 & 1.035 & 1845 & 874 & 871 & 60 & 250 & 250 & 1.32 & 1892 & 877 & 866 & 60 & 260 & 260 & 1,32 \\
\hline 0.05 & Original & 0.997 & 1.022 & 1812 & 815 & 806 & 40 & 210 & 210 & 1.69 & 1875 & 833 & 823 & $50:$ & 220 & 210 & 1.60 \\
\hline 0.05 & Reduced & 1.008 & 1.028 & 1842 & 864 & 854 & 60 & 230 & 220 & 1.44 & 1888 & 855 & 846 & 50 & 230 & 230 & 1.45 \\
\hline 0.10 & Original & 0.978 & 1.003 & 1822 & 771 & 763 & 40 & 110 & 110 & 2.70 & 1887 & 783 & 775 & 40 & 110 & 100 & 2.75 \\
\hline
\end{tabular}


Table VIII. Effect of 0.2 Sec Delay in Scram for $\Delta P=0.02$, Reduced $G_{0}^{\prime} s, 2.03 \mathrm{Sec}$ After Start of Transient

\begin{tabular}{|c|c|c|c|c|c|c|}
\hline & \multicolumn{3}{|c|}{ Channe1 1} & \multicolumn{3}{|c|}{ Channe1 2} \\
\hline & $\frac{\text { Max }}{\text { Fue1 }}$ & $\frac{\text { Temp. }{ }^{\circ} \mathrm{C}}{\text { Coolant }}$ & $\begin{array}{l}\text { Boiling (a) } \\
\text { Time, Sec }\end{array}$ & $\frac{\text { Max }}{\text { Fue1 }}$ & $\frac{\text { Temp. }{ }^{\circ} \mathrm{C}}{\text { Coolan } t}$ & $\begin{array}{l}\text { Boiling } \\
\text { Time, Sec }\end{array}$ \\
\hline $\begin{array}{l}\text { Original } \\
\text { Scram }\end{array}$ & 1327 & 905 & $\begin{array}{l}3.03 \\
\text { (extrap) }\end{array}$ & 1341 & 901 & $\begin{array}{l}3.10 \\
\text { (extrap) }\end{array}$ \\
\hline $\begin{array}{l}\text { Delayed } \\
\text { Scram }\end{array}$ & 1408 & 941 & 2.18 & 1427 & 939 & 2.05 \\
\hline
\end{tabular}

(a) Based on boiling temperature of $950^{\circ} \mathrm{C}$ 